(2) Open Access Full Text Article

\title{
Levonorgestrel-releasing intrauterine systems for long-acting contraception: current perspectives, safety, and patient counseling
}

This article was published in the following Dove Press journal:

International Journal of Women's Health

13 October 2016

Number of times this article has been viewed

\section{Dustin J Costescu}

Department of Obstetrics and Gynaecology, McMaster University, Hamilton, ON, Canada
Correspondence: Dustin J Costescu HSC 2F45, I 200 Main Street West, Hamilton, ON L8N 3Z5, Canada

$\mathrm{Tel}+19055212100$

Email costesd@mcmaster.ca

\begin{abstract}
Unintended pregnancy is a significant global problem. In 2008, there were over 100 million unplanned pregnancies worldwide, representing approximately $41 \%$ of global conceptions. Family planning strategies in many countries are shifting from increasing the uptake of contraception among nonusers to increasing the uptake of the most effective methods among users of less effective methods. One of the most effective and acceptable methods of contraception is the levonorgestrel-releasing intrauterine system (LNG IUS); however, its uptake varies widely by country. This article reviews the currently available LNG IUSs, the rationale for increasing uptake of these methods, and evidence regarding safety, and discusses counseling strategies to best inform women about this option for contraception.
\end{abstract}

Keywords: LNG IUS, long-acting contraception, intrauterine contraception, levonorgestrel, contraception, family planning

\section{Introduction}

Unintended pregnancy is a significant global phenomenon. In a multinational study of over 80 countries, it is estimated that $41 \%$ of conceptions worldwide, over 100 million annually, are unplanned. ${ }^{1}$ Rates vary by jurisdiction: $37 \%$ are unintended in Oceania, $38 \%$ in Asia, 44\% in Europe, $48 \%$ in North America, and $63 \%$ in South America. ${ }^{1}$ Rates of unintended pregnancy are declining in all jurisdictions except for North America.

One of the most effective options for pregnancy prevention is the levonorgestrelreleasing intrauterine system (LNG IUS). Precise estimates of use of LNG IUS are difficult to obtain, as many countries report the use of any intrauterine contraception (IUC), a definition that includes both LNG IUS and copper intrauterine device (CuIUD). Worldwide, approximately $20 \%$ of women use IUC, but use varies widely; in Canada, about $1 \%-2 \%$ of women use IUC, whereas in China, $41 \%$ use IUC. ${ }^{2}$ In most jurisdictions, use of IUC and LNG IUS is low, given their effectiveness, and increased uptake shows promise in making further reductions in unintended pregnancy rates.

This article reviews LNG IUSs with respect to their role in contraception, riskbenefit profile, and features that should be discussed with women considering this method.

\section{The need for long-acting contraception: the Canadian experience}

In Canada, precise estimates of unintended pregnancy are difficult to obtain, but a recent economic evaluation suggests that $39 \%$ of pregnancies are unintended, translating to 
over 180,000 unintended pregnancies and 65,000 unintended births annually. ${ }^{3,4}$ The direct medical cost of unintended pregnancy in Canada alone is approximately CAD 320 million, whereas raising unintended offspring costs Canadian families between CAD 4 and 15 billion. ${ }^{3}$

Unintended pregnancy occurs in one of two settings: conception occurs among couples not using contraception or conception occurs as a result of contraceptive failure. In North America, 50\% of unintended pregnancies occur as a result of contraceptive failure (due to either imperfect adherence or inherent method failure). ${ }^{5}$

While it is important to inform women and couples about contraception, simply increasing contraceptive uptake is insufficient to make ongoing reductions in unplanned pregnancy in many jurisdictions. For instance, contraceptive use in Canada is high; among women who do not wish to conceive, $15 \%$ are not using contraception, whereas $20 \%$ are using a method inconsistently or incorrectly. ${ }^{6}$ Contraceptive nonuse is more common among women at decreased risk of unintended pregnancy; they are more likely to be ambivalent about a pregnancy, older, less fertile, and have lower coital frequency. $^{7}$

Conversely, the most commonly used methods of contraception in Canada are condoms, combined oral contraception, and withdrawal. ${ }^{6}$ These methods carry a typical-use failure rate of $18 \%, 9 \%$, and $22 \%$, respectively. ${ }^{7,8}$ IUC is uncommonly used in Canada relative to other countries. ${ }^{6}$ Therefore, significant reductions in unintended pregnancy and its associated costs could be made if women switched from these less effective methods to the most effective methods. ${ }^{4}$

\section{A changing reproductive lifecycle}

The needs of women with respect to family planning continue to change. Women born in the 1950s could expect to delay childbearing by 4 to 5 years from the onset of first intercourse. ${ }^{9,10}$ Since then, age at first intercourse has decreased slightly, but the age of first marriage and first childbirth has increased significantly. The median age of first childbirth in 2011 was 28.5 years, and the proportion of first births occurring in women over 30 years is increasing. ${ }^{10}$ This means that young women can expect to delay childbearing by nearly 12 years from first intercourse. With such expectations for contraception, there is an increased need for the most effective options.

Furthermore, not all first marriages last forever. With decreasing rates of marriage, high rates of separation and divorce, and increasing subsequent marriages and long-term relationships, some, but not all, women may wish to preserve fertility rather than consider permanent contraception in the form of tubal sterilization. ${ }^{11}$ Poststerilization regret is the most common complication following permanent contraception. ${ }^{12}$ Thus, long-acting contraception (LAC; also called long-acting reversible contraception) shows potential at both ends of the reproductive lifecycle.

\section{LNG IUS: an overview}

An elegant and concise history of IUC is provided by Speroff and Darney in their clinical handbook for contraception. ${ }^{13}$ In 1979, the first paper describing an LNG-releasing device in rhesus monkeys was published, ${ }^{14}$ with the first human studies involving an LNG-releasing intrauterine device (IUD) published in $1980 .{ }^{15}$ In the early $1980 \mathrm{~s}$, the first LNG IUS studies were published, which characterized the effectiveness and bleeding patterns of such devices. ${ }^{16}$ A 1-year LNG IUS was produced with limited uptake. Thereafter, a $52 \mathrm{mg}$ device with a daily release rate of $20 \mu \mathrm{g} /$ day was approved in Finland in 1993 for conception control (LNG IUS 20, total content 52 mg; Mirena; Bayer AG, Leverkusen, Germany). ${ }^{17}$

\section{Currently available LNG IUS}

There are several LNG IUSs available worldwide. The technical specifications are summarized in Table 1, with additional clinical information as follows.

\section{LNG IUS 20}

The LNG IUS $20(20 \mu \mathrm{g} /$ day release rate, total content 52 mg/day; Mirena; Bayer AG) was first approved in 1993

Table I Key features of the commercially available LNG IUS

\begin{tabular}{|c|c|c|c|c|c|}
\hline Device (brand name) & $\begin{array}{l}\text { Total LNG } \\
\text { content }\end{array}$ & $\begin{array}{l}\text { Daily LNG } \\
\text { rate }^{\mathrm{a}}\end{array}$ & $\begin{array}{l}\text { Device } \\
\text { dimensions }\end{array}$ & $\begin{array}{l}\text { Failure rate (I-year } \\
\text { pearl index) }\end{array}$ & $\begin{array}{l}\text { Approved duration } \\
\text { of use }\end{array}$ \\
\hline LNG IUS 20 (Mirena) & $52 \mathrm{mg}$ & $20 \mu \mathrm{g} /$ day & $32 \times 32 \mathrm{~mm}$ & 0.2 & 5 years \\
\hline LNG IUS 8 (Jaydess/Skyla) & $13.5 \mathrm{mg}$ & $8 \mu \mathrm{g} / \mathrm{day}$ & $28 \times 28 \mathrm{~mm}$ & 0.41 & 3 years \\
\hline LNG20 (Levosert/Liletta) & $52 \mathrm{mg}$ & $18.6 \mu g / d a y$ & $32 \times 32 \mathrm{~mm}$ & 0.15 & 3 years (likely to increase) \\
\hline LNG IUS 9 (Kyleena) & 19.5 mg & $9 \mu \mathrm{g} / \mathrm{day}$ & $28 \times 28 \mathrm{~mm}$ & 0.16 & 5 years \\
\hline
\end{tabular}

Note: approximate release rate, which varies over life of in situ device. Data from ${ }^{18-20,22}$.

Abbreviations: LNG IUS, levonorgestrel-releasing intrauterine system; LNG, levonorgestrel. 
in Finland, with approvals worldwide at different times. It is placed using a one-handed inserter with a $4.4 \mathrm{~mm}$ insertion tube. ${ }^{18}$ LNG IUS 20 is considered the gold standard LNG IUS, with over 2,000 studies published on its many uses in gynecology and family planning. LNG IUS 20 is approved in most countries worldwide for contraception, in many countries for heavy menstrual bleeding, and in some countries for endometrial protection during hormone replacement therapy.

\section{LNG IUS 8}

In 2013, a smaller-framed device was approved for conception control for 3 years (LNG IUS $8 \mu \mathrm{g}$ daily release rate, total content $13.5 \mathrm{mg}$; Jaydess/Skyla; Bayer Healthcare, Whippany, NJ, USA). It contains a small silver ring (to allow for differentiation between LNG IUS 20) and is placed with a one-handed inserter with an insertion tube of $3.8 \mathrm{~mm}$ diameter. It is approved only for conception control. ${ }^{19}$

\section{LNG20}

In 2012, a new $52 \mathrm{mg}$ LNG IUS was approved in the UK (LNG20, total content $52 \mathrm{mg}$; Levosert/Liletta; Allergan PLC, Irvine, CA, USA). The LNG20 has an initial daily release rate of $18.6 \mu \mathrm{g} / \mathrm{day}$, and is placed with a two-handed inserter with an insertion tube of $4.8 \mathrm{~mm}$ diameter. ${ }^{20}$ The device is currently undergoing phase III studies. The current duration of use is 3 years, but it will increase as phase III data show effectiveness. In countries where LNG20 is approved, it is less expensive than LNG IUS 20. It is approved for both conception control and heavy menstrual bleeding.

\section{LNG IUS 9}

In 2015, Bayer Healthcare submitted a New Drug Application to the US Food and Drug Administration and the European Medicines Agency for LNG IUS 9 (total content $19.5 \mathrm{mg}$ ). This device has been approved by the FDA in September $2016 .{ }^{21}$ As approval was obtained by the FDA at the time of final copyediting of this article, this device will not be discussed in detail. Published clinical data for LNG IUS 9 is available via phase II and III trials for both the $13.5 \mathrm{mg}$ (LNG IUS 8) and 19.5 mg (LNG IUS 9) devices. ${ }^{22,23}$

\section{Mechanism of action}

The primary mechanism of contraceptive effect of all LNG IUSs is thickening of cervical mucus, which results in the impairment or inability of sperm to fertilize an oocyte. ${ }^{18-20}$ As such, LNG IUSs are not abortifacients. ${ }^{24}$ Thickened cervical mucus may confer additional benefits to women, such as potentially reduced upper genital tract infection/ pelvic inflammatory disease (PID).

The secondary mechanisms of action are clinically important but, in vivo, are not thought to play a significant role in preventing conception. Firstly and most notably, progestins cause endometrial decidualization and quiescence, leading to reduced and/or absent menstrual blood flow. While this also impairs endometrial receptivity of a blastocyst; this has not been demonstrated in vivo. Secondly, in some women, the progestin secretion of an LNG IUS is sufficient to prevent ovulation. Thirdly, progestins may impair tubal motility, reducing the potential fertile window of an oocyte. Fourthly, the presence of an intrauterine foreign body may accelerate apoptosis of spermatozoa, oocytes, and blastocysts through a sterile inflammatory response; this is more clearly understood with copper-containing devices as opposed to inert plastic devices. Furthermore, because progestins decrease prostaglandin production (a proposed mechanism by which dysmenorrhea is reduced), this mechanism of action may not exist for LNG IUS. ${ }^{24}$

\section{Key features}

LNG IUSs share a set of common characteristics. LNG IUSs are highly effective LACs, with typical-use failure rates less than $0.5 \%$ of users. ${ }^{8,22,24}$ Satisfaction is high among women who are accepting of reduced or absent menstrual flow. ${ }^{25}$ They are also referred to as "forgettable" contraception, as they require almost no effort on the part of women to maintain adherence. Once removed, fertility is rapidly restored. ${ }^{26,27}$

\section{Indications}

The shared indication of all LNG IUSs is conception control, and is the focus of this review. Additional indications vary by country. ${ }^{18-20}$ The LNG IUS 8 (total content $13.5 \mathrm{mg}$ ) is approved for conception control in nulliparous and parous women for 3 years. ${ }^{19}$ There are no other approved indications for this device, but it does reduce dysmenorrhea and may have additional clinical benefits which will evolve with time. ${ }^{23}$ LNG20 (total content $52 \mathrm{mg}$ ) is currently approved for conception control and management of idiopathic heavy menstrual bleeding for 3 years. ${ }^{20}$ As pivotal trials are ongoing, the duration of indication will change with time.

The established LNG IUS 20 (total content $52 \mathrm{mg}$ ) is approved for conception control for 5 years. ${ }^{18}$ In many countries, it is also approved for the treatment of heavy menstrual bleeding, and in fewer countries, for endometrial protection during hormone replacement therapy. ${ }^{18,28}$ With the recent publication of a 7-year randomized controlled trial of 
the World Health Organization (WHO) showing effectiveness at 7 years, it is unclear if the duration of indication will change. ${ }^{29}$ Additional unapproved uses of the LNG IUS 20 are too numerous to list in this paper.

In the original pivotal trials involving LNG IUS 20, only parous women were included, ${ }^{14,16}$ and as a result, in some product monographs, clinicians are advised that it is "not a first-line method" for nulliparous women. This is not an evidence-informed statement. ${ }^{3,24}$ While parity may be considered as part of patient counseling and device selection, it should not preclude a nulliparous woman of reproductive age from using an LNG IUS.

\section{Contraindications}

Contraindications, based on the WHO Medical Eligibility Criteria for contraceptive use (WHO-MEC), are listed in Table 2. The WHO-MEC assigns a rating out of 4 based on risk-benefit profile. A category 4 is a contraindication (previously considered absolute contraindication), whereas category 3 condition indicates that risk outweighs benefit (relative contraindication). Either the low-frequency providers should generally avoid prescribing a method to a woman with an MEC-3 or MEC-4 condition, or the woman should be referred for expert consultation. ${ }^{29,30}$

\section{Safety}

\section{Addressing patient concerns}

Despite the many positive features of IUC, and in particular, LNG IUS, uptake is low in many countries. ${ }^{2,3,6}$ There are numerous barriers to uptake of IUC: systemic, clinician-driven, and patient-driven. A common barrier is related to the safety of such devices. ${ }^{3}$ Addressing myths (held beliefs for which there are no data to support, or where data refute such beliefs) and misperceptions (where the risk is anticipated to be much higher or severe than evidence supports) can allay fears and improve adherence. Women who express dissatisfaction with counseling are more likely to discontinue their method. ${ }^{7}$

When counseling regarding IUC use, I suggest responding to patient concerns clearly, using objective data and accurate estimates of risk, usually presented as numerical data, rather than being dismissive ("that's not a problem at all", "I've never had a patient experience that complication") or alarmist ("it is a serious risk, but if you still want an IUD I will refer you"). Be mindful of agreeing with patients in a way that reinforces a misperception or myth (eg, Patient: "I hear IUDs cause infections" Clinician: "Yes, many patients share that concern").

This section reviews the specific risks associated with LNG IUS use.

\section{Failure}

No method of contraception is $100 \%$ effective; however, the failure rates of intrauterine systems (IUSs) are among the lowest of all methods. The failure rate of LNG IUS 20 and LNG20 is effectively the same as female tubal sterilization. ${ }^{8,24}$ The failure rate of LNG IUS 8 ( $13.5 \mathrm{mg}$ device) is 0.33 per 100 woman-years over the 3 years, and 0.31 for LNG IUS 16 (19.5 mg device), which is only slightly higher than the failure rate of sterilization, and is in stark contrast to the $9 \%$ failure rate of combined hormonal pills, patches, and rings. ${ }^{8}$

In Canada, we recommend that typical-use failure rate be used when discussing any method of contraception, as

Table 2 Contraindications to use of an LNG IUS, based on the WHO Medical Eligibility Criteria

\begin{tabular}{ll}
\hline Category $\mathbf{4}$ - do not use & Category $\mathbf{3}$ - risk outweighs benefit \\
\hline Pregnancy & Insertion 48 hours to less than 4 weeks postpartum \\
Puerperal sepsis & Acute venous thromboembolism \\
Immediately post-septic abortion & Current/history of ischemic heart disease (continuation of an LNG IUS) \\
Unexplained vaginal bleeding that has not been adequately investigated & SLE with unknown or positive antiphospholipid antibodies \\
GTN and increasing $\beta$-hCG levels & Migraines with aura (continuation) \\
Cervical cancer awaiting treatment (insertion) & GTN and stable or decreasing $\beta$-hCG levels \\
Current breast cancer & Past breast cancer (more than 5 years and no evidence of disease) \\
Endometrial cancer (insertion) & Increased risk of STI (two out of three) (insertion) \\
Ovarian cancer (insertion) & Advanced HIV/AIDS (insertion) \\
Uterine leiomyoma with distortion of cavity & Pelvic tuberculosis (continuation) \\
Distortion of the uterine cavity that is incompatible with IUD insertion & Severe cirrhosis \\
Current PID or mucopurulent cervical discharge (insertion) & Malignant hepatoma \\
Pelvic tuberculosis (insertion) & Hepatocellular adenoma \\
\hline
\end{tabular}

Notes: In some circumstances, a disease state may preclude the insertion of an IUS, but if a disease occurs with and IUS in place, it can be left alone. In such cases, the condition is labelled "(insertion)". In a few conditions, the new onset of disease in an IUS user precludes continued use. These are labelled "(continuation)".

Abbreviations: LNG IUS, levonorgestrel-releasing intrauterine system; WHO, World Health Organization; SLE, systemic lupus erythematosus; GTN, gestational trophoblastic neoplasia; $\beta$-hCG, beta-human chorionic gonadotropin; STI, sexually transmitted infection; IUD, intrauterine device; PID, pelvic inflammatory disease; IUS, intrauterine system. 
this represents the "real-world" use of a method, and factors discontinuation and adherence. ${ }^{12}$ While patients may offer an anecdote of a "friend" who experienced a failure of an IUD or IUS, I remind them that the rarity of such an event is what makes it memorable.

There are increasing data that show LNG IUSs continue to provide conception control beyond the approved indication. ${ }^{29-31}$ When insurance coverage and patient means permit, the device should be replaced at the end of its approved indication. However, if a woman has an IUS in situ beyond the approved duration and cannot afford another method, it may be reasonable to leave the device in situ for an additional duration of 1 year (LNG IUS 8) or 2 years (LNG IUS 20/LNG20) with informed discussion about a possibly increased risk of unintended pregnancy.

\section{Pregnancy with an IUS in situ}

When a pregnancy occurs with an IUS in situ, pregnancy options counseling should take place first. If the desire is for the pregnancy to continue, and the strings are visible, the IUS should be removed as soon as possible. If the desire is for abortion, the IUS should be removed (if possible) prior to medical abortion, or at the time of surgical abortion. ${ }^{32}$ If strings are not seen, expulsion or perforation should also be considered as possible mechanisms for failure.

\section{Ectopic pregnancy}

The ectopic pregnancy rate (number of ectopic pregnancies per year) is reduced among IUS users. ${ }^{13}$ This is owing to the high effectiveness of IUSs. Like for CuIUDs and tubal sterilization, pregnancies that occur in the setting of a placed IUS are more likely to be ectopic than with a spontaneous conception. In the EURAS IUD study, a postmarketing surveillance study of IUD and IUS users, the proportion of ectopic pregnancies among conceptions in IUS users was $27 \%$, versus $15 \%$ for CuIUD users. ${ }^{33}$ As such, if a woman becomes pregnant with an IUS in situ, ectopic pregnancy must rapidly be ruled out. Because it can be confusing to compare absolute and conditional risks, a graphical representation of the incidence may be useful (Figure 1).

\section{Pain}

Fear of a painful placement is a common concern among women. In most cases, women experience little or no pain with placement. In a phase II study of two low-dose LNG IUSs, $57.9 \%$ experienced no or mild pain in the LNG IUS

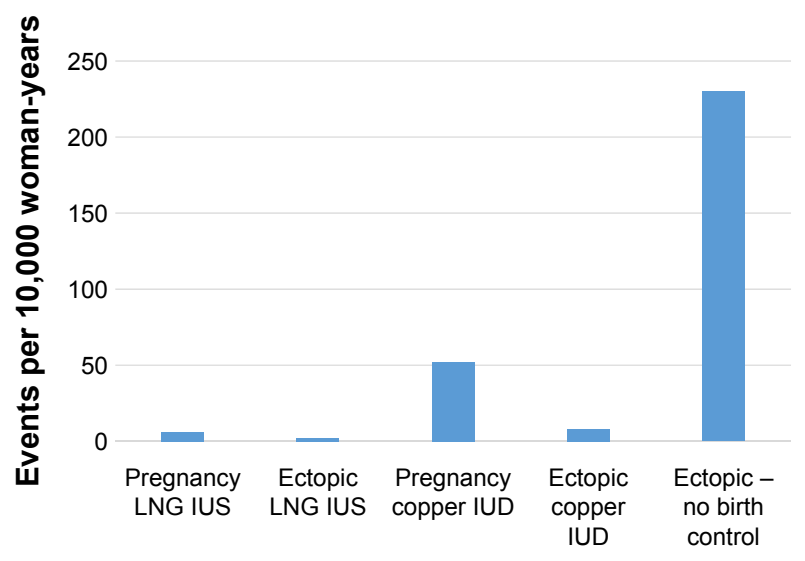

Figure I Relative frequencies of intrauterine pregnancy and ectopic pregnancy in IUC users and in the general population. ${ }^{33,55}$

Abbreviations: IUC, intrauterine contraception; LNG IUS, levonorgestrel-releasing intrauterine system; IUD, intrauterine device.

20 cohort, and $72.3 \%$ experienced no or mild pain in $\mathrm{LNG}$ IUS 8/9 group. ${ }^{23}$ In a study of over 2,000 women undergoing a first-time LNG IUS placement, the median level of pain on a $10 \mathrm{~cm}$ visual analog scale $(10 \mathrm{~cm}=$ worst imaginable pain) was 1. Nulliparous women experienced more pain (mean $2.7 \mathrm{~cm}$ ) than parous women (mean $1.9 \mathrm{~cm}$ ), but, clinically, both are low. ${ }^{34} \mathrm{We}$ have seen similar results in our center.

Risk factors for pain during placement include a history of dysmenorrhea, history of cervical instrumentation, and a previous difficult insertion. ${ }^{23,24,34}$ For all women, verbal reassurance ("vocal local") and guidance throughout the placement can be extremely helpful. Distraction techniques (eg, coughing at the time of tenaculum placement) can also be useful. ${ }^{24}$

The use of additional interventions to reduce pain with insertion shows minimal benefit. ${ }^{35}$ Paracervical and intracervical blocks show limited benefit when performed routinely; these are best reserved for difficult placements. Misoprostol increases pain with insertion and should not be used routinely. ${ }^{35}$

\section{Perforation}

Uterine perforation with IUC placement most often occurs at the time of insertion. However, migration is reported remote from a confirmed correct placement (likely due to perforation from a sound or device inserter prior to correct intrauterine placement). ${ }^{36}$ While perforation is a common concern of women and clinicians, it is a rare complication. Reported rates of perforation vary in the literature; however, the largest cohort study that examined this complication was a postmarketing surveillance study in Europe of 
61,000 women who received an IUS. ${ }^{37}$ Among IUS users, the rate of perforation was 1.4 per 1,000 women (one in 714 placements). Risk factors for perforation include postpartum state and breastfeeding. Reassuringly, among 61,000 women, no woman experienced a life-threatening complication related to perforation. In this study, only LNG IUS 20 was studied. A subsequent study involving LNG IUS 8 is currently underway.

\section{Infection}

No review on IUC safety is complete without a nod to the Dalkon Shield, an inert plastic IUD that was associated with an increased incidence of PID, related to the multifilament string. ${ }^{13}$ Since then, fears about PID related to IUC use have been difficult to alleviate.

Infections related to IUC placement are related to ascension of lower genital tract flora into the upper genital tract, and occur within the first 1 to 3 months following placement. ${ }^{24}$ Conversely, in women with preexisting chlamydial infection, the presence of an IUC was not associated with an increased risk of PID when compared to those women without an IUC. ${ }^{38}$

Infections following IUC placement are uncommon, affecting approximately $0.54 \%$ of insertions. ${ }^{39}$ Rates of PID were similar among women who were unscreened, prescreened, and screened at the time of IUC placement. Because it is more cost-effective, and potentially avoids the barrier of unnecessary pelvic examinations, same-day, risk factor-based screening (under 26 years, history of sexually transmitted infection [STI], or non-monogamy) is preferable. ${ }^{39}$

Because the risk of PID is independent of the use of IUC, women with a history of STI and women who are at increased risk of STI can safely use an IUS. However, if a woman has mucopurulent cervical discharge, insertion should be delayed. ${ }^{24}$

\section{Infection with an IUS in situ}

While uncommon, pelvic infections can occur with an IUS in situ. Asymptomatic infections can be treated while leaving the IUS in place. ${ }^{24}$ One notable exception is when actinomyces or actinomyces-like effects are seen on a cervical cytology smear; in such cases, no treatment is warranted.

When mild-to-moderate PID occurs in a woman using an IUS, it should be left in situ while treatment is initiated. If a woman does not respond clinically within 48 hours, it should then be removed. In cases of severe PID (eg, tubo-ovarian abscess or sepsis), or if a woman requests removal at the time of diagnosis, it may be preferable to remove the IUS once IV antibiotic therapy has been established, to reduce the risk of seeding infection.

\section{Expulsion}

Expulsion occurs when the device is partially or completely extruded through the cervical os. It occurs most often in the first 1 to 3 months following placement, and is rare beyond this interval. The reported rates of expulsion are variable; most estimates are between 3 and $5 \% .{ }^{24}$ In a large US study of contraceptive users, IUD expulsions were more common in adolescents, but parity did not affect expulsion risk. ${ }^{40}$ Post-placement ultrasonography should be reserved for difficult placements and when side effects or complications arise. $^{24}$

\section{Low placement}

In our center, we frequently receive consultations from clinicians who order routine scans, only to find that an IUS is "low", either in the lower segment or in the cervix. If the woman is asymptomatic, it can be left in situ, and she should be instructed to perform string checks periodically. If a follow-up ultrasound is ordered, it should be repeated in 3 months, when many IUSs will migrate to the fundal position. ${ }^{41}$ Because the mechanism of action of an IUS is cervical mucus thickening, it will function in a "low" position; this differs from CuIUDs, where sufficient intrauterine copper ion concentrations must be maintained to exert a contraceptive effect. ${ }^{42}$

\section{Infertility}

A concern among many clinicians and younger women is that IUC use is associated with infertility. ${ }^{43}$ Many studies examining IUC use and infertility examined the CuIUDs, and evidence for LNG IUS is more limited, though reassuring. Fertility is rapidly restored following removal of an IUS, with $80 \%-92 \%$ of women conceiving within a year of LNG IUS removal. ${ }^{26}$ In a follow-up study of 69 IUC (50 LNG IUS) users and 42 nonusers, 12-month fertility rates were similar ( $81 \%$ former IUC user, $70 \%$ nonusers), and were actually higher among nulliparous IUC users than nonusers $(92 \%$ versus $61 \%, P=0.02) .{ }^{27}$ Women should be informed that fertility declines with age, and at the end of a 5-year device, older women may have experienced a decrease in ovarian reserve during that time. ${ }^{12}$

\section{Improving the patient experience}

One barrier to IUC uptake is the perception that counseling regarding IUC/IUS is too lengthy for clinicians with limited time. ${ }^{3}$ The US Contraceptive CHOICE study, which 
Table 3 TIC-TAC approach to brief contraception method selection

$\mathrm{T}-$ What is the Timeline until the next pregnancy?

I - Are there any non-contraceptive Indications (eg, dysmenorrhea)?

$\mathrm{C}$ - Are there any Contraindications (eg, history of thrombosis)?

$\mathrm{T}$ - What have you Tried before? What did you like/not like about it?

A - Is there Anything else that you are interested in trying?

C - Do you have drug Coverage? (How do you pay for drugs?)

demonstrated high uptake of IUS and a resultant significant reduction in unintended pregnancy, provided structured counseling sessions for its participants, with a mean time of 12.9 minutes (range $4-32$ ) ${ }^{44} \mathrm{With}$ some advanced preparation, repetition, and confidence, complete counseling regarding LNG IUS need not be lengthy.

\section{Narrowing the options}

Women who require contraception may benefit from access to general contraception counseling tools, such as videos or websites, prior to their appointment. In our clinic, women have the option of watching a short, non-branded video which outlines the currently available options, starting with the most effective options.

Various approaches and strategies for contraception counseling have been reported. A simple six-question approach (TIC-TAC, Table 3) can be helpful to narrow the options down to one or two. A shared decision-making approach is preferred: one where the clinician and woman work together to find an optimal method. ${ }^{45}$ In addition to effectiveness, side effects and adherence should be discussed. Once the method selection has been narrowed down, the woman should make the final choice.
Some women have previous experience with CuIUDs. Delineating the differences between the two devices may be helpful, and is summarized in Table 4.

\section{Patient selection}

Most women can safely use LNG IUS. A list of contraindications is provided in Table 2 . There are certain populations that warrant additional discussion, as they tend to be overlooked as IUS candidates.

\section{Adolescents}

Adolescents can expect to delay conception for 10 years or more from the onset of sexual activity. ${ }^{9,10}$ As such, they are excellent candidates for LAC. The Society of Obstetricians and Gynaecologists of Canada, the American College of Obstetricians and Gynecologists, the Society of Family Planning, and the American Academy of Paediatrics support the use of IUC in women of any age, including adolescent women. ${ }^{24,46-48}$

Both the LNG IUS 20 and LNG IUS 8 have been studied in adolescents. In the Contraceptive CHOICE project, $31 \%$ of women under 20 years chose LNG IUS 20 (24.6\% 14- to 17-year olds; $35.4 \%$ 18- to 19 -year olds). ${ }^{49}$ Continuation rate at 1 year was $81 \%$ among nulliparous women under 20 years. ${ }^{50}$ A phase III LNG IUS 8 profiling study involving 303 adolescents (12- to 17-years old) was recently published. In this study, no pregnancies occurred at 1 year, and there were no cases of PID (there was a single case of endometritis, treated without complication). ${ }^{51}$

Adolescents may benefit from additional counseling regarding menstrual changes with IUS and the safety of

Table 4 Differences between LNG IUS and copper IUDs

\begin{tabular}{|c|c|c|}
\hline & Levonorgestrel IUS & Copper IUD \\
\hline \multirow[t]{4}{*}{ Mechanism of action } & Cervical mucus thickening (major) & Spermatotoxic reaction (major) \\
\hline & Decreased tubal motility and endometrial & Accelerated apoptosis of released oocyte \\
\hline & receptivity (minor) & (minor) \\
\hline & & Decreased endometrial receptivity (minor) \\
\hline \multirow[t]{2}{*}{ Effect on menstrual flow } & May be reduced or absent & Typically increased by $0.5-1$ day per cycle, \\
\hline & Spotting may occur in lieu of menses & up to 2 days per cycle is normal \\
\hline Effect on dysmenorrhea & Typically decreased & May increase \\
\hline \multirow[t]{3}{*}{ Moliminal symptoms } & May reduce symptoms via reduced blood flow & Unchanged as it is hormone-free \\
\hline & Women may experience transient breast & \\
\hline & tenderness in first few months & \\
\hline Can be used for emergency & No & Yes \\
\hline \multicolumn{3}{|l|}{ contraception } \\
\hline Cost & Typically more expensive but may be covered & Lowest daily cost of any contraceptive but \\
\hline & under drug plan & may not be covered under drug plans \\
\hline Failure rate & $0.2-0.3$ per 100 woman-years & 0.8 per 100 woman-years \\
\hline
\end{tabular}

Abbreviations: LNG IUS, levonorgestrel-releasing intrauterine system; IUD, intrauterine device; IUS, intrauterine system. 
amenorrhea. Women worried about pain may benefit from the use of a smaller-framed device. ${ }^{23}$

\section{Nulliparous women}

The initial trials for LNG IUS 20 included only parous women. ${ }^{14,16}$ In many jurisdictions, most notably Europe, the product labeling for IUS states that it is not a first-line contraceptive for nulliparous women. ${ }^{52}$ However, this is not evidence-based. The Society of Family Planning and the Society of Obstetricians and Gynaecologists of Canada state that IUC can be used as first-line therapy in nulliparous women. ${ }^{24,47}$

\section{Perimenopausal women}

The LNG IUS is a very good option for midlife women who require contraception. A common clinical question arises as to when the IUS should be removed if the woman is amenorrheic. Follicle-stimulating hormone will not be suppressed by progestin-only methods. If elevated above 35 IU/L over two readings, the woman should be considered menopausal, and the IUS can be removed. If the woman experiences vasomotor symptoms, estrogen replacement therapy (ET) can be initiated with an LNG IUS 20 or LNG20 in situ. Neither the LNG IUS 8 nor LNG IUS 9 has been studied for endometrial protection during ET; however, a $10 \mu \mathrm{g} /$ day LNG menopausal intrauterine system (that was not marketed) demonstrated adequate endometrial protection during use of oral ET. ${ }^{53}$

\section{Informed consent}

The benefits of an LNG IUS should be discussed with the woman, including the high effectiveness, low ease of adherence, and rapid reversibility. Potential beneficial effects on menses should be articulated as well. Clinicians should be sure to inform women of the material risks of an LNG IUS. Precise risk estimates are most useful, as they allow women to judge for themselves if this is a risk worth taking. The key risks are summarized as a rapid reference in Table 5.

\section{Placement}

A pelvic examination is not required until placement is to be attempted. In the product labeling for each of the IUSs, placement should occur within the first 7 days following a normal menstrual period. However, placement can occur anytime it is reasonably certain that a woman is not pregnant. A summary, as described in the WHO Selected Practice Recommendations for Contraceptive Use, is provided in Table 6. Urine pregnancy testing is not evidence-informed in most cases, and may miss very early conceptions. In instances where recent sexual activity has taken place, emergency contraception, such as a CuIUD, should be considered.

The steps of placement should be reviewed with the woman, and any last-minute concerns should also be reviewed. Cleansing the cervix with antiseptic solution is optional. ${ }^{24}$ We highly recommend the use of a tenaculum, as uterine traction will reduce the axis of a uterus, making insertion easier, and in some cases, possible. I ask patients to cough at the time of tenaculum to provide distraction. Few interventions have demonstrated significant reduction in pain at the time of IUS insertion; therefore, routine use of paracervical blockade is not recommended. ${ }^{35}$

The uterus should be sounded prior to opening the sterile packaging. The minimum uterine depth should be $6 \mathrm{~cm}$, and the maximum, $10 \mathrm{~cm}$. If the depth is beyond $10 \mathrm{~cm}$, perforation should be considered, and the procedure should be stopped. ${ }^{36}$ If less than $6 \mathrm{~cm}$, expulsion and malplacement are more likely. Sounding also provides a sense of the discomfort women will experience with IUS placement. I always warn women to expect discomfort at $4 \mathrm{~cm}$ on the sound; coaching women through the uncomfortable steps provides reassurance.

Once the arms are released from the IUS, a pause of ten seconds should take place before advancing the device

Table 5 Key risks and risk estimates required for informed counseling regarding LNG IUS

\begin{tabular}{|c|c|}
\hline \multirow[t]{2}{*}{ Pregnancy } & 0.2 per I,000 (LNG IUS 20, I year), 0.15 per I,000 (LNG20, I year), 0.33 per I,000 (LNG IUS 8,3 years) \\
\hline & Ectopic pregnancy is reduced, but risk of ectopic pregnancy is $27 \%$ if pregnant with IUS in situ \\
\hline Infection & Risk of PID is $0.54 \%$, usually within first 3 months and related to preexisting infection \\
\hline \multirow[t]{2}{*}{ Perforation } & Risk of perforation is one in 714 \\
\hline & More common in postpartum period and breastfeeding period \\
\hline Expulsion & $3 \%-5 \%$, usually within first 3 months following placement \\
\hline Unscheduled bleeding & $\begin{array}{l}\text { Irregular bleeding and spotting is common but may persist with some women. One-year amenorrhea occurs in } \\
\text { approximately } 24 \% \text { of LNG IUS } 20 \text { users, } 19 \% \text { of LNG } 20 \text { users, and I } 2 \% \text { of LNG IUS } 8 \text { users }\end{array}$ \\
\hline Pain & $2-3$, on a 10 -point visual analog scale, at the time of insertion \\
\hline
\end{tabular}

Note: Data from studies. ${ }^{8,18,20,23,33,37,39}$

Abbreviations: LNG IUS, levonorgestrel-releasing intrauterine system; LNG, levonorgestrel; IUS, intrauterine system; PID, pelvic inflammatory disease. 
Table 6 Ruling out pregnancy prior to IUS insertion

You can be reasonably certain a woman is not pregnant if she says yes to any of the following criteria:

Within the first 7 days of a last normal menses

Anytime in a cycle if no sexual activity since her last normal menses Currently using an effective form of contraception

Within 2 weeks of a first- or second-trimester abortion

Within 3 weeks of a term pregnancy, if not breastfeeding

She is correctly using lactational amenorrhea (less than 6 months postpartum, no menses, and fully breastfeeding)

Otherwise, steps should be taken to rule out pregnancy, and/or consider emergency contraception (including a copper IUD)

Note: Data from Centers for Disease Control and Prevention. ${ }^{54}$

Abbreviations: IUS, intrauterine system; IUD, intrauterine device.

to the fundus. The arms are slow to open in the uterus, and perforation may be reduced by waiting. Having women count, take deep breaths, and wiggle toes all seem to be effective options for distraction in our clinic.

\section{Follow-up}

A follow-up visit 6-12 weeks following placement allows the opportunity to review side effects, address concerns, and assess for adverse events. Routine string checks may be performed in some centers, though they only need to be performed if there is a concern. ${ }^{54}$ Routine ultrasound is not recommended, and should be reserved for difficult insertions, or when clinically indicated. ${ }^{24}$ Women should be informed of the date after which the IUS should be replaced.

\section{Conclusion}

LNG IUSs are highly effective, highly acceptable forms of LAC which can be used across the entire reproductive lifecycle. Increased uptake of LNG IUS has been shown to reduce unintended pregnancy, and has the potential to significantly reduce medical costs as well as societal costs from rising unintended births. Clinicians play an important role in reducing access barriers for women who need highly effective contraception and would consider an LNG IUS to meet this need.

\section{Disclosure}

Dustin Costescu did not receive any compensation (direct or in-kind) for the completion of this manuscript. He has served on national and international advisory boards for Bayer AG and Allergan PLC, both of whom manufacture LNG-containing intrauterine systems. The author reports no other conflicts of interest in this work.

\section{References}

1. Sedgh G, Singh S, Hussain R. Intended and unintended pregnancies worldwide in 2012 and recent trends. Stud Fam Plann. 2014;45(3):301-314.
2. World Health Organization. World contraceptive use 2015. Available from: http://www.un.org/en/development/desa/population/publications/ dataset/contraception/wcu2015.shtml. Accessed June 30, 2016.

3. Hauck B, Costescu D. Barriers and misperceptions limiting widespread use of intrauterine contraception among Canadian women. $J$ Obstet Gynaecol Can. 2015;37(7):606-616.

4. Black AY, Guilbert E, Hassan F, et al. The cost of unintended pregnancy in Canada: estimating direct cost, role of imperfect adherence, and the potential impact of increased use of long acting reversible contraceptives. J Obstet Gynaecol Can. 2015;37(12):1086-1097.

5. Finer LB, Henshaw SK. Disparities in rates of unintended pregnancy in the United States, 1994 and 2001. Perspect Sex Reprod Health. 2006; 38(2):90-96.

6. Black A, Wang Q, Wu Wen S, Lalonde AB, Guilbert E, Fisher W. Contraceptive use among Canadian women of reproductive age: results of a national survey. J Obstet Gynaecol Can. 2009;31(7):627-640.

7. Pazol K, Whiteman MK, Folger SG, Kourtis AP, Marchbanks PA, Jamieson DJ. Sporadic contraceptive use and nonuse: age-specific prevalence and associated factors. Am J Obstet Gynecol. 2015;212(3): 324.e1-324.e8.

8. Trussell J. Contraceptive failure in the United States. Contraception. 2011;83(5):397-404.

9. Finer LB, Philbin JM. Trends in ages at key reproductive transitions in the United States, 1951-2010. Womens Health Issues. 2014;24(3): e271-e279.

10. Statistics Canada. Fertility: fewer children, older moms. Available from: http://www.statcan.gc.ca/pub/11-630-x/11-630-x2014002-eng. htm. Accessed June 30, 2016.

11. Statistics Canada. Marital status: overview, 2011. Catalogue No. 91-201-X. 2013

12. Black A, Guilbert D, Costescu D, et al. Canadian contraception consensus (Part 2). J Obstet Gynaecol Can. 2015;37(11):1033-1039.

13. Speroff L, Darney P. Intrauterine contraception. In: A Clinical Guide for Contraception. Philadelphia, PA: Lippincott Williams \& Wilkins; 2011.

14. Nilsson CG, Lähteenmäki P, Luukkainen T. Patterns of ovulation and bleeding with a low levonorgestrel-releasing intrauterine device. Contraception. 1980;21(2):155-164.

15. Wadsworth PF, Heywood R, Allen DG, Sortwell RJ, Walton RM. Treatment of rhesus monkeys (Macaca mulatta) with intrauterine devices loaded with levonorgestrel. Contraception. 1979;20(2):177-184.

16. Nilsson CG, Luukkainen T, Diaz J, Allonen H. Intrauterine contraception with levonorgestrel: a comparative randomised clinical performance study. Lancet. 1981;1(8220):577-580.

17. Luukkainen T, Allonen H, Haukkamaa M, Lähteenmäki P, Nilsson CG, Toivonen J. Five years' experience with levonorgestrel-releasing IUDs. Contraception. 1986;33(2):139-148.

18. Bayer Healthcare Canada. Mirena product monograph. 2014. Available from: http://omr.bayer.ca/omr/online/mirena-pm-en.pdf. Accessed June 30, 2016.

19. Bayer Healthcare Canada. Jaydess product monograph. 2014. Available from: http://omr.bayer.ca/omr/online/jaydess-pm-en.pdf. Accessed June 30, 2016.

20. Allergan Specialty Pharmaceuticals. Liletta prescribing information. Available from: www.allergan.com/assets/pdf/liletta_pi. Accessed June 30, 2016.

21. Bayer Healthcare Pharmaceuticals. Press release. Available from: http://www.prnewswire.com/news-releases/bayer-submits-new-drugapplication-for-lcs-16-for-pregnancy-prevention-for-up-to-five-years300182419.html. Accessed June 30, 2016.

22. Nelson A, Apter D, Hauck B, et al. Two low-dose levonorgestrel intrauterine contraceptive systems: a randomized controlled trial. Obstet Gynecol. 2013;122(6):1205-1213.

23. Gemzell-Danielsson K, Schellschmidt I, Apter D. A randomized, phase II study describing the efficacy, bleeding profile, and safety of two low-dose levonorgestrel-releasing intrauterine contraceptive systems and Mirena. Fertil Steril. 2012;97(3):616-622. 
24. Black A, Guilbert E, Costescu D, et al. Canadian contraception consensus - chapter 7 - intrauterine contraception. J Obstet Gynaecol Can. 2016;38(2):182-222.

25. Peipert JF, Zhao Q, Allsworth JE, et al. Continuation and satisfaction of reversible contraception. Obstet Gynecol. 2011;117(5):1105-1113.

26. Sivin I, Stern J, Diaz S, et al. Rates and outcomes of planned pregnancy after use of Norplant capsules, Norplant II rods, or levonorgestrelreleasing or copper TCu $380 \mathrm{Ag}$ intrauterine contraceptive devices. Am J Obstet Gynecol. 1992;166(4):1208-1213.

27. Stoddard AM, Xu H, Madden T, Allsworth JE, Peipert JF. Fertility after intrauterine device removal: a pilot study. Eur J Contracept Reprod Health Care. 2015;20(3):223-230.

28. UK Medicines and Healthcare Products Regulatory Agency/eMC. Mirena - summary of product characteristics (SPC). Available from: www.medicines.org.uk/emc/medicine/1829/spc/mirena. Accessed June 30, 2016

29. Rowe P, Farley T, Peregoudov A, et al. Safety and efficacy in parous women of a 52-mg levonorgestrel-medicated intrauterine device: a 7-year randomized comparative study with the TCu380A. Contraception. 2016;93(6):498-506.

30. World Health Organization. Medical eligibility criteria for contraceptive use, 5th edition. 2015. Available from: www.who.int/reproductivehealth/ publications/family_planning/MEC-5/en/. Accessed June 30, 2016.

31. Creinin MD, Jansen R, Starr RM, Gobburu J, Gopalakrishnan M, Olariu A. Levonorgestrel release rates over 5 years with the Liletta $52 \mathrm{mg}$ intrauterine system. Contraception. Epub 2016 Apr 25.

32. Costescu D, Guilbert E, Black A, et al. SOGC clinical practice guideline: medical abortion. J Obstet Gynaecol Can. 2016;38(4):366-389.

33. Heinemann K, Reed S, Moehner S, Minh TD. Comparative contraceptive effectiveness of levonorgestrel-releasing and copper intrauterine devices: the European Active Surveillance Study for Intrauterine Devices. Contraception. 2015;91(4):280-283.

34. Hubacher D, Reyes V, Lillo S, Zepeda A, Chen PL, Croxatto H. Pain from copper intrauterine device insertion: randomized trial of prophylactic ibuprofen. Am J Obstet Gynecol. 2006;195(5):1272-1277.

35. Lopez LM, Bernholc A, Zeng Y, et al. Interventions for pain with intrauterine device insertion. Cochrane Database Syst Rev. 2015;(7): CD007373.

36. Ferguson CA, Costescu D, Jamieson MA, Jong L. Transmural migration and perforation of a levonorgestrel intrauterine system: a case report and review of the literature. Contraception. 2016;93(1):81-86.

37. Heinemann K, Reed S, Moehner S, Minh TD. Risk of uterine perforation with levonorgestrel-releasing and copper intrauterine devices in the European Active Surveillance Study on Intrauterine Devices. Contraception. 2015;91(4):274-279.

38. Jatlaoui TC, Simmons KB, Curtis KM. The safety of intrauterine contraception initiation among women with current asymptomatic cervical infections or at increased risk of sexually transmitted infections. Contraception. Epub 2016 Jun 1.

39. Sufrin CB, Postlethwaite D, Armstrong MA, Merchant M, Wendt JM, Steinauer JE. Neisseria gonorrhea and Chlamydia trachomatis screening at intrauterine device insertion and pelvic inflammatory disease. Obstet Gynecol. 2012;120(6):1314-1321.

40. Madden T, McNicholas C, Zhao Q, Secura GM, Eisenberg DL, Peipert JF. Association of age and parity with intrauterine device expulsion. Obstet Gynecol. 2014;124(4):718-726.
41. Faundes D, Perdigao A, Faundes A, Bahamondes L, Petta CA. T-shaped IUDs accommodate in their position during the first 3 months after insertion. Contraception. 2000;62(4):165-168.

42. Ratsula K, Toivonen J, Lahteenmaki P, Luukkainen T. Plasma levonorgestrel levels and ovarian function during the use of a levonorgestrelreleasing intracervical contraceptive device. Contraception. 1989; 39(2):195-204.

43. Payne JB, Sundstrom B, DeMaria AL. A qualitative study of young women's beliefs about intrauterine devices: fear of infertility. J Midwifery Womens Health. 2016;61(4):482-488.

44. Madden T, Mullersman JL, Omvig KJ, Secura GM, Peipert JF. Structured contraceptive counseling provided by the Contraceptive CHOICE Project. Contraception. 2013;88(2):243-249.

45. Dehlendorf C, Krajewski C, Borrero S. Contraceptive counseling: best practices to ensure quality communication and enable effective contraceptive use. Clin Obstet Gynecol. 2014;57(4):659-673.

46. Committee on Adolescent Health Care Long-Acting Reversible Contraception Working Group, The American College of Obstetricians and Gynecologists. Committee opinion no. 539: adolescents and long-acting reversible contraception: implants and intrauterine devices. Obstet Gynecol. 2012;120(4):983-988.

47. Society of Family Planning. Use of the Mirena IUS and Paragard CuT380A intrauterine devices in nulliparous women. Contraception. 2010;81:5(2010):367-371.

48. American Academy of Pediatrics. Contraception for adolescents. Pediatrics. 2014;134(4):e1244-e1256.

49. Secura GM, Madden T, McNicholas C, et al. Provision of no-cost, long-acting contraception and teenage pregnancy. NEngl J Med. 2014; 371(14):13161323.

50. Abraham M, Zhao Q, Peipert JF. Young age, nulliparity, and continuation of long-acting reversible contraceptive methods. Obstet Gynecol. 2015;126(4):823-829.

51. Gemzell-Danielsson K, Buhling KJ, Dermout SM, Lukkari-Lax E, Montegriffo E, Apter D. A Phase III, single-arm study of LNG-IUS 8, a low-dose levonorgestrel intrauterine contraceptive system (total content $13.5 \mathrm{mg}$ ) in postmenarcheal adolescents. Contraception. 2016; 93(6):507-512.

52. Bayer Limited (Ireland). Mirena: summary of product characteristics. Available from: http://www.medicines.ie/medicine/2707/SPC/ Mirena+52mg+Intrauterine+Delivery+System/. Accessed June 30, 2016.

53. Raudaskoski T, Tapanainen J, Tomás E, et al. Intrauterine 10 microg and 20 microg levonorgestrel systems in postmenopausal women receiving oral oestrogen replacement therapy: clinical, endometrial and metabolic response. BJOG. 2002;109(2):136-144.

54. Centers for Disease Control and Prevention. U.S. selected practice recommendations for contraceptive use, 2013: adapted from the World Health Organization selected practice recommendations for contraceptive use, 2nd edition. MMWR. 2013;62(RR05):1-46.

55. Stulberg DB, Cain LR, Dahlquist I, Lauderdale DS. Ectopic pregnancy rates and racial disparities in the Medicaid population, 2004-2008. Fertil Steril. 2014;102(6):1671-1676.
International Journal of Women's Health

\section{Publish your work in this journal}

The International Journal of Women's Health is an international, peerreviewed open-access journal publishing original research, reports, editorials, reviews and commentaries on all aspects of women's healthcare including gynecology, obstetrics, and breast cancer. The manuscript management system is completely online and includes
Dovepress

a very quick and fair peer-review system, which is all easy to use. Visit http://www.dovepress.com/testimonials.php to read real quotes from published authors. 